\title{
Anti-DR5 mAb inhibits proliferation of human fibroblast-like synovial cells and reduces their cytokine secretion in vitro
}

This article was published in the following Dove Press journal:

OncoTargets and Therapy

29 September 2015

Number of times this article has been viewed

\author{
Minping Zhang ${ }^{1,2, *}$ \\ Chunyan Shil,* \\ Chun $\mathrm{Xia}^{3}$ \\ Jin Yang' \\ Xingyang Niu' \\ Guohong Zhuang' \\ Ping Yin ${ }^{4}$ \\ 'Organ Transplantation Institute, \\ Anti-Cancer Research Center, Medical \\ College, Xiamen University, Xiamen, \\ ${ }^{2}$ The Department of Pharmacy, First \\ Hospital, Nanping, ${ }^{3}$ The Department \\ of Orthopaedics, ${ }^{4}$ The Department \\ of Pathology, Xiamen Zhongshan \\ Hospital, Xiamen University, Xiamen, \\ Fujian, People's Republic of China \\ *These authors contributed equally \\ to this work
}

\begin{abstract}
Background: We have previously reported that anti-death receptor 5 (DR5) monoclonal antibody (mAb) is therapeutically effective in the treatment of rheumatoid arthritis (RA) in a collagen-induced arthritis rat model. However, the molecular mechanism and the effect of antiDR5 $\mathrm{mAb}$ on proapoptotic genes and cytokine secretion in the human fibroblast-like synovial cells (FLS) requires further clarification. This study may provide new evidence for the application of anti-DR5 $\mathrm{mAb}$ as a treatment for RA.
\end{abstract}

Methods: Human FLS were isolated from patients with RA and were treated with anti-DR5 mAb. An MTT assay and flow cytometry were used to detect the induction of apoptosis in vitro. Cytokine secretion by the FLS was detected using the enzyme-linked immunosorbent assay. The mRNA expression was assessed by reverse transcription polymerase chain reaction, and the protein expression was analyzed by Western blot. The apoptotic pathway was investigated further using a caspase inhibition assay.

Results: Anti-DR5 mAb-induced apoptosis in human RA FLS in vitro. The protein expressions of caspase- $8,-3$, and -9 were decreased in human anti-DR5 $\mathrm{mAb}$-treated FLS in a dose-dependent manner through exposure to a caspase inhibitor, indicating that anti-DR5 mAb induction of apoptosis is through the caspase pathway. Decreased levels of tumor necrosis factor- $\alpha$ (TNF- $\alpha$ ) and interferon- $\gamma($ IFN- $\gamma$ ) were detected after treatment with anti-DR5 mAb in vitro.

Conclusion: Anti-DR5 mAb may induce apoptosis in human FLS through the caspase pathway and through decreased secretions of TNF- $\alpha$ and IFN- $\gamma$.

Keywords: death receptor 5, rheumatoid arthritis, apoptosis

\section{Introduction}

Rheumatoid arthritis (RA) is an autoimmune disease that results in an increase of inflammatory cytokines in the synovial fluid, with synovial thickening and bone damage that can eventually lead to joint deformity. The main pathologic characteristics of RA are related to the abnormal inflammatory cytokine secretion in the synovial tissue and an abnormal proliferation of synovial cells in the joint. ${ }^{1}$ Few cells in the joint normally display the morphologic features of apoptosis as assessed by electron microscopy. ${ }^{2}$

The proinflammatory cytokines tumor necrosis factor- $\alpha$ (TNF- $\alpha$ ) and IL-1 play a crucial role in the pathogenesis of arthritis by driving the enhanced production of cytokines, chemokines, and degradative enzymes. ${ }^{3}$ Increased numbers of proinflammatory Th1/Th0 cells have been reported in the synovial membrane of RA patients, triggering pannus formation. ${ }^{4}$

Similar to Fas, death receptor 5 (DR5) is a death receptor that binds to a recently identified cytokine, the TNF-related apoptosis-inducing ligand (TRAIL). The anti-DR5 monoclonal antibody ( $\mathrm{mAb}$ ) has been reported to induce cell apoptosis in various types 
of cancer cells. ${ }^{5,6}$ Wang et $\mathrm{al}^{7}$ reported that the $\mathrm{mAb}$ against DR5 A6 causes a reduction in the viability of Jurkat cells in both a time- and dose-dependent manner, and this was attributed to the activation of an apoptotic pathway. We previously reported that anti-DR5 $\mathrm{mAb}$ ameliorated adjuvant arthritis in rats by inducing apoptosis in the synovial cells, ${ }^{8}$ because highly proliferative synovial cells play a crucial role in bone erosion and cartilage destruction in RA. Although DR5 can induce apoptosis in fibroblast-like synovial cells (FLS), the effects of anti-DR $5 \mathrm{mAb}$ on the secretion of inflammatory cytokines has not yet been reported. Therefore, FLS were obtained from human RA patients, and apoptosis was induced by applying anti-DR5 $\mathrm{mAb}$ with a caspase inhibitor. We then examined whether caspases 3, 8, and 9 were activated in FLS taken from human RA patients and the effects of a caspase-specific inhibitor, ie, the broad-spectrum caspase inhibitor Z-VADFMK (Bi Yuntian, Jiangsu, People's Republic of China), on the recovery of the loss of viability caused by treatment with the anti-DR5 mAb. In addition, the effect of the anti-DR5 treatment on cytokine secretion by FLS was assessed.

\section{Materials and methods}

\section{Tissues and primary synovial cells}

The synovial tissues and primary tissues were taken from RA patients in Xiamen Zhongshan Hospital (Xiamen, People's Republic of China) who needed joint replacements between September 2011 and December 2012. All samples were obtained with patient consent and with the approval of the Committee on Medical Ethics of Zhongshan Hospital, Xiamen University (Xiamen, People's Republic of China). After removing adipose tissue, the synovial tissues were cut into small pieces and then washed three times with $200 \mathrm{mg} / \mathrm{L}$ D-Hanks (without $\mathrm{Ca}^{2+}$ or $\mathrm{Mg}^{2+}$ ) and with $200 \mathrm{kU} / \mathrm{L}$ penicillin and streptomycin added. Next, $2 \mathrm{~mL}$ of DMEM (Thermo Fisher Scientific, Waltham, MA, USA) without fetal bovine serum and $2 \mathrm{~mL} 0.2 \%$ type II collagenase (Thermo Fisher Scientific) were added to the tissue pieces (each piece was less than $1 \mathrm{~g}$, with a total of approximately ten pieces). These were then digested for 4 hours at $37^{\circ} \mathrm{C}, 5 \% \mathrm{CO}_{2}$. The nonadherent cells (the adherent cells were synovial tissue macrophage-like cells) were digested with $0.25 \%$ trypsin for 30 minutes at $37^{\circ} \mathrm{C}, 5 \% \mathrm{CO}_{2}$. The mixture was filtrated through a 200 -mesh nylon net to remove the connective tissue, and the synovial cells were separated by centrifugation for 10 minutes at 2,000 rpm. These subcultured cells were then cultured in DMEM at $37^{\circ} \mathrm{C}$ in an atmosphere of $5 \% \mathrm{CO}_{2}$ in an incubator. The entire medium was supplemented with $10 \%$ heat-inactivated fetal calf serum (Luoshen, Shanghai, People's Republic of China) and $100 \mathrm{U} / \mathrm{mL}$ penicillin and streptomycin. The cells were digested by $0.05 \%$ trypsin with $0.02 \%$ EDTA and subcultured.

\section{Preparation of peripheral blood mononuclear cells}

Citrate-anticoagulated peripheral blood was obtained from all subjects. After Ficoll-Paque Plus (GE Healthcare Bio-Sciences AB, Uppsala, Sweden) density gradient centrifugation, interface mononuclear cells were collected and washed three times with phosphate-buffered saline (PBS).

\section{Immunofluorescence}

After three periods of generation, the synovial cells covered approximately $60 \%$ of the slide. Human peripheral blood mononuclear cells (PBMCs) were taken as the positive control group because their $\mathrm{CD} 14$ expression is very high. The cells were then fixed with a $4 \%$ paraformaldehyde solution for 15 minutes, and then they were perforated by $0.2 \%$ Triton $\mathrm{X}-100$ for 10 minutes at room temperature. The cells were incubated with anti-vimentin antibody (1:100; Epitomics, Inc., Burlingame, CA, USA) at room temperature for $30 \mathrm{~min}$ utes. The cells were observed on a fluorescence microscope (Olympus IX71) at a magnification of 20×.

\section{Generation of anti-DR5 mAb}

The DR5 gene was constructed by overlapping polymerase chain reaction (PCR) and was then cloned into pET-22b(b), which contained a six-histidine tag. The DR5 used in this study was purified through a nickel ion column (Novagen, Billerica, MA, USA). All the experiments were performed using 6- to 8-week-old female BALB/c mice purchased from the Model Animal Research Center of Xiamen University Medical College. All the animals were housed under specific pathogen-free conditions with constant access to water and chow. All experimental procedures were carried out following approval of the Animal Care and Using Committee of Xiamen University. BALB/c mice were immunized with sDR5. The mice were boosted three times and the splenocytes were fused with SP2/0-Ag 14 in the presence of 50\% polyethylene glycol in complete serum-free DMEM, followed by culturing in DMEM/hypoxanthine, aminopterin and thymidine and DMEM/hypoxanthine and thymidine (Sigma-Aldrich Co., St Louis, MO, USA) selective media. Using ELISA, the supernatants from positive wells were tested for the presence of antibodies that bind sDR5. Hybridomas that produced antibodies that can bind sDR5 underwent three rounds of limiting dilution analysis. Next, $\mathrm{mAb}$ isotypes were determined by ELISA using a mouse immunoglobulin isotyping ELISA kit (Pharmingen,San 
Diego, CA, USA). The mAb used in this study was purified by protein $\mathrm{G}$ affinity chromatography (Pierce, Rockford, IL, USA). Protein purification was performed as previously described. ${ }^{8}$

\section{The FITC-labeled anti-DR5 antibody}

A $100 \mathrm{~mL}$ solution of anti-DR5 was adjusted to $3 \mathrm{mg} / \mathrm{mL}$ using $0.5 \mathrm{~mol} / \mathrm{L}$ (pH 9.0) $\mathrm{Na}_{2} \mathrm{CO}_{3}$ buffer and normal saline. Then, $1.3 \mathrm{mg}$ of FITC was gradually added to the anti-DR5 solution over the course of approximately 5-10 minutes, and the solution was stirred for 12 hours at $4{ }^{\circ} \mathrm{C}$ in the dark. Then, the anti-DR5 solution was centrifuged (2,500 rpm) for 20 minutes to remove a small amount of sediment, put into a dialysis bag, and then placed in beaker of $\mathrm{pH} 9.0$ saline buffer $\left(0^{\circ} \mathrm{C}-4^{\circ} \mathrm{C}\right)$ overnight. The protein concentration of the conjugate was measured according to the absorbance at 280 and $495 \mathrm{~nm}$. The FITC-labeled anti-DR5 antibody conjugate was stored at $-20^{\circ} \mathrm{C}$ until further use.

\section{MTT analysis}

FLS $\left(1 \times 10^{4} /\right.$ well $)$ were added in quintuplicate in a 96-well plate (Corning Incorporated, Corning, NY, USA) in the presence of various concentrations of anti-DR5 mAb (1.6, 3.2, $6.3,12.5,25$, and $50 \mu \mathrm{g} / \mathrm{mL}$ ), and then these cells were cultured in DMEM with $10 \%$ fetal bovine serum, at $37^{\circ} \mathrm{C}$ in an atmosphere of $5 \% \mathrm{CO}_{2}$, and incubated for 24 hours. Then, $20 \mu \mathrm{L}$ of MTT solution ( $5 \mathrm{mg} / \mathrm{mL}$ ) was added to each well, followed by incubation for 4 hours. The supernatant was then removed from all wells. Then, $150 \mu \mathrm{L}$ DMSO was added to each well to dissolve the formazan crystal produced from the MTT. Finally, the OD value was tested with a multi-scanner auto-reader at $490 \mathrm{~nm}$.

\section{DR5 expression and cell apoptosis were detected by flow cytometry}

FLS were trypsinized lightly, washed with PBS (with 2\% BSA), and then incubated with $1 \mu \mathrm{g}$ anti-DR5-FITC antibody for 1 hour at $4^{\circ} \mathrm{C}$. Before being detected by flow cytometry, the cells were washed three times with PBS (with 2\% BSA). Finally, the cells were analyzed in a flow cytometer (BD Biosciences, San Jose, CA, USA). For apoptosis, FLS were harvested by $0.25 \%$ trypsin (without EDTA), then doublestained for annexin V conjugated with FITC and propidium iodide (Kaiji, Nanjing, People's Republic of China) and then analyzed by flow cytometry.

\section{Hoechst staining}

Cells $\left(1 \times 10^{6}\right)$ were incubated with $50 \mu \mathrm{g} / \mathrm{mL}$ mouse $\mathrm{IgG}$ or anti-DR5 mAb for 24 hours. Hoechst 33342 staining solution (5 $\mu \mathrm{g} / \mathrm{mL}$; Sijiqing, Hangzhou, People's Republic of China) was added to the FLS, which were incubated at room temperature for 30 minutes. The cells were removed from the incubator and the staining solution was washed out. Finally, the cells were viewed on a fluorescence microscope (Olympus IX71) at magnifications of $20 \times$ and $40 \times$.

\section{Detection of TNF- $\alpha$ and IFN- $\gamma$ secretion}

Samples of the cultured cell fluid were centrifuged at 5,000 rpm for 10 minutes to obtain the supernatant. The supernatant was diluted three times. The expressions of TNF- $\alpha$ and interferon- $\gamma$ (IFN- $\gamma$ ) in the supernatant dilution were detected with an ELISA kit. Finally, a multi-scanner auto-reader was used (MR 5000; Dynatech, Chantilly, VA, USA) at $450 \mathrm{~nm}$ to read the absorbance values.

\section{Quantitative PCR and reverse transcription PCR analysis}

The total RNA was isolated using the TRIzol reagent (Thermo Fisher Scientific) and purified with RNeasy Mini kits (Qiagen NV, Venlo, the Netherlands) according to the manufacturer's instructions.

After processing with RNase-free DNase I (Thermo Fisher Scientific), the RNA samples were reversely transcribed with oligo(dT) and SuperScript II transcriptase (Thermo Fisher Scientific). Quantitative PCR was performed using specific Quantitect primers for human $\beta$-actin, TNF- $\alpha$, and IFN- $\gamma$ (Qiagen NV) in an Applied Biosystems 7500 system using Power SYBR Green PCR Master Mix (Thermo Fisher Scientific). Relative gene expression levels were determined using $\beta$-actin as the control. The relative quantification of PCR products was expressed as $2^{-\Delta \Delta C t}$ Representative results were obtained from three independent experiments.

The expressions of TNF- $\alpha$ and IFN- $\gamma$ mRNA were analyzed by reverse transcription PCR. The conditions used were one cycle at $94^{\circ} \mathrm{C}$ for 3 minutes followed by 30 cycles at $94^{\circ} \mathrm{C}$ for 30 seconds, $58^{\circ} \mathrm{C}$ for 30 seconds, $72^{\circ} \mathrm{C}$ for 1 minute, and $72^{\circ} \mathrm{C}$ for 5 minutes. Each sample was normalized to $\beta$-actin level.

\section{Western blot analysis}

Aliquots (30 $\mu \mathrm{g}$ of protein) of cell lysate were separated on a $12 \%$ SDS-PAGE gel, blotted into a nylon membrane, and probed with antibodies against caspase-3, active caspase-3, procaspase-8, caspase-9, and active caspase-9 (Epitomics, Inc.). Membranes were washed with 1\% Tween 20 in tris buffered saline and incubated with a 1:3,000 dilution of HRP-conjugated secondary antibodies (Huaan, Hangzhou, 
People's Republic of China) for 1 hour at room temperature. Protein bands were visualized by their enhanced chemiluminescence reaction.

\section{Caspase inhibition assay}

The MTT assay was used to further investigate whether anti-DR5 mAb induces FLS apoptosis through the caspase pathway. FLS $\left(1 \times 10^{4} /\right.$ well $)$ were incubated in a 96 -well plate, and then various concentrations $(0,5,10,15,20,25,30$, and $35 \mu \mathrm{M})$ of caspase inhibitor Z-VAD-FMK were added. After 30 minutes, anti-DR5 mAb $(50 \mu \mathrm{g} / \mathrm{mL})$ was added, then MTT analysis was used to test after 24 hours. The subsequent steps were the same as the MTT analysis.

\section{Statistical analysis}

Data were presented as the mean \pm standard deviation per group. Statistical analysis was made for multiple comparisons using analysis of variance and the Student's $t$-test. A $P$-value $<0.05$ was considered to be statistically significant.

\section{Results}

\section{Isolation and identification of human FLS}

The primary culture of synovial cells included type A, B, and C cells. ${ }^{9}$ The cells assumed very different shapes (Figure 1A). The morphologies of the primary cultured synovial cells were inhomogeneous and included both round and irregular shapes. Type A cells were round or irregularly shaped and had a distinct nucleolus. The morphology of type B cells was uniform and fusiform (Figure 1B). Type B cells are also known as FLS. Type C cells are intermediate cells, and they were found only rarely. Using adherent digestion, only type $B$ cells remained after three passages because type A cells do not proliferate, leaving only the type B cells, or FLS, adhered and growing on the culture dish.

Type B cells have been reported to strongly express vimentin and not to express CD14 (Figure 1C). ${ }^{10}$ Thus, we verified that the cells adhering to the flask were type B cells by staining for vimentin and CD14. As shown in Figure 1D, the cells were all green, indicating positive expression of vimentin. The expression of CD14 in the isolated cells was only $1.16 \%$, as shown in Figure $1 \mathrm{E}$ and F. However, the expression of CD14 in PBMCs was $88.80 \%$. Therefore, the cells adhering to the wall were identified as FLS.

\section{Anti-DR5 mAb induces apoptosis of FLS}

We used an MTT assay to determine whether anti-DR5 mAb inhibited the proliferation of human FLS in vitro. As shown in Figure 2A, when human FLS were treated with anti-DR5
$\mathrm{mAb}$ at $1.6 \mu \mathrm{g} / \mathrm{mL}$ for 24 hours, the cell death rate was $6.6 \% \pm 0.9 \%$, but when the concentration of anti-DR $5 \mathrm{mAb}$ was increased to $50 \mu \mathrm{g} / \mathrm{mL}$, the cell death rate increased to $53.2 \% \pm 2.0 \%$. This dose dependence in inhibition suggests that anti-DR5 mAb may inhibit the proliferation of synovial cells.

We further examined the DR5 expression by synovial cells and the apoptosis rate of human FLS after treatment with anti-DR5 mAb by using flow cytometry. Compared with the control group, with the increased concentration of anti-DR5, the DR5 expression had increased from $17.10 \%$ to $45.90 \%$, and the apoptosis rate had risen from $0.03 \%$ to $34.87 \%$ (Figure 2B-E). We concluded that anti-DR5 mAbinduced apoptosis in human FLS in vitro, and that this was related to the expression of DR5 on the cell surface.

Using Hoechst 33342 dye solution to stain human FLS after anti-DR5 mAb treatment, the cells were found to be round and their nuclei splintered (Figure 2F). These results also indicated that anti-DR5 mAb had induced FLS apoptosis.

\section{Anti-DR5 mAb-induced FLS apoptosis through the caspase pathway}

Analysis of the expression of proteins involved in the apoptosis pathway revealed that the levels of procaspase-3 and -8 were increased with increasing concentrations of anti-DR5 $\mathrm{mAb}$ (Figure 3A and B). Compared with the PBS group (0 $\mu \mathrm{g} / \mathrm{mL}$ anti-DR5 $\mathrm{mAb}$ treatment group), the expressions of procaspase- 3 and -8 were higher in the $50 \mu \mathrm{g} / \mathrm{mL}$ anti-DR5 $\mathrm{mAb}$ treatment group.

To verify the mechanism of anti-DR5 mAb-induced apoptosis via the caspase pathway, we added various concentrations of caspase inhibitor to the FLS treated with antiDR5 $\mathrm{mAb}$. The caspase inhibitor inhibited the induction of apoptosis by anti-DR5 mAb. The inhibitory effect was dose dependent from 0 to $35 \mu \mathrm{M}$, as shown in Figure $3 \mathrm{C}$.

Furthermore, the expressions of procaspase- 9 and -3 and active caspase- 9 and -3 were increased after the FLS were treated with anti-DR5 mAb. However, after the addition of the caspase, these all decreased when compared with the anti-DR5 mAb group (Figure 3D and E). These results demonstrated that anti-DR5 mAb-induced FLS apoptosis through the caspase pathway.

\section{Anti-DR5 mAb decreased the expressions of TNF- $\alpha$ and IFN- $\gamma$ by human FLS}

The levels of TNF- $\alpha$ and IFN- $\gamma$ in the cell culture supernatant of RA FLS were both decreased when compared with 

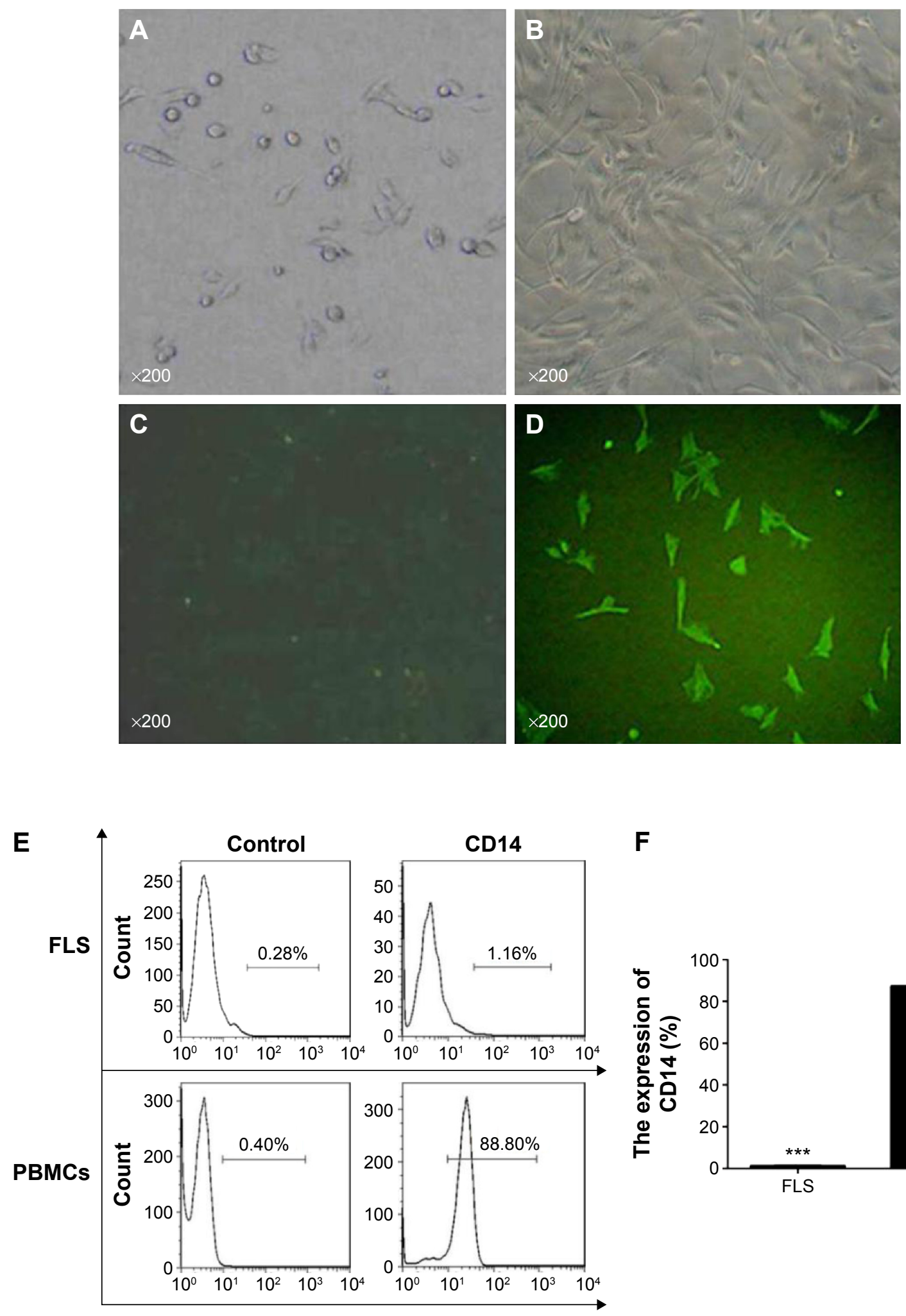

$\mathbf{F}$

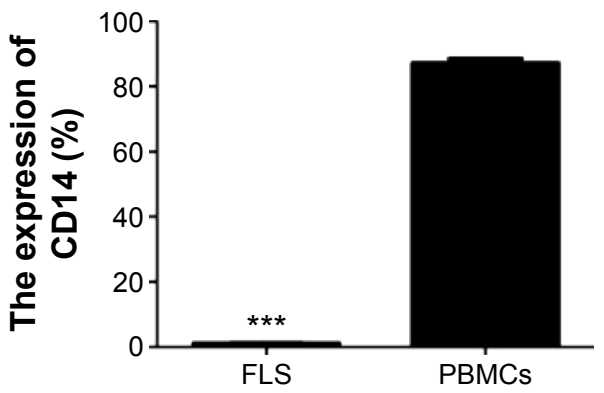

Figure I Identification and culture of synovial cells from rheumatoid arthritis patients.

Notes: The synovial cells were obtained from synovial tissue using trypsin combined with type II collagenase. Synovial cells included types A, B, and C. The morphologies of the primary cultured synovial cells were inhomogeneous, including round and irregular-shaped cells, whereas the morphology of type B cells was uniform and fusiform. Using adherent digestion, only type B cells remained after three passages because type A type cells do not have the capacity to proliferate, leaving only type B, or fibroblastlike synovial cells (FLS), adhered and growing on the culture dish. Type B cells strongly express vimentin and do not express CDI4. Human peripheral blood mononuclear cells (PBMCs) were used as a positive control because they highly express CDI4. (A) Images showing that the morphologies of the primary cultured synovial cells were inhomogeneous. (B) Images showing that the morphology of cultured synovial cells were uniform after the third passage. (C) Passage 3 synovial cells were stained with a rabbit secondary antibody coupled to FITC as a control. (D) Passage 3 synovial cells were stained with an anti-vimentin antibody and a rabbit secondary antibody coupled to FITC. (E and F) Passage 3 synovial cells and PBMCs were incubated with a mouse secondary antibody coupled to FITC as controls. The expression of CDI4 in passage 3 synovial cells and PBMCs was detected by flow cytometry after incubation with a CDI4 antibody and mouse secondary antibody coupled to FITC. ***P $<0.000$ I vs PBMCs. 


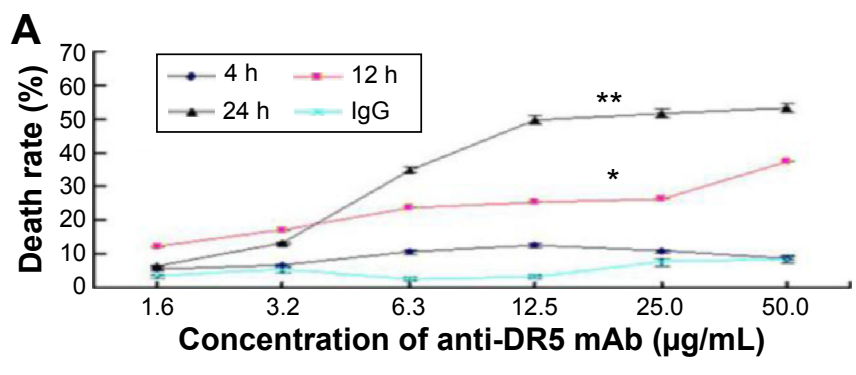

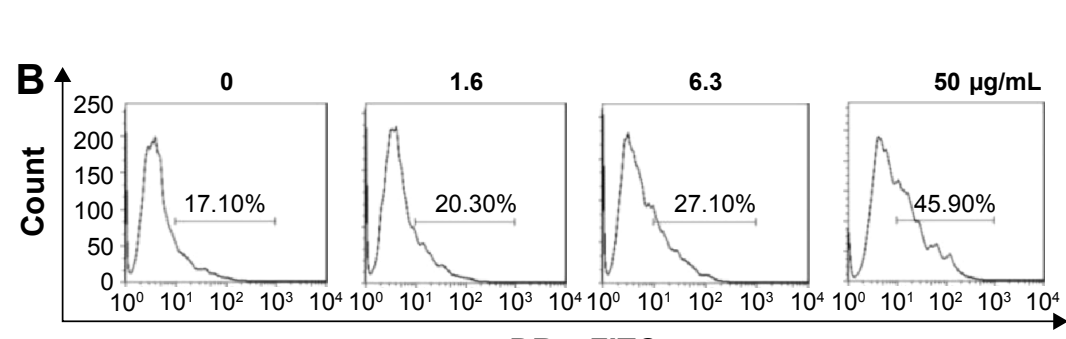

DR5-FITC

D

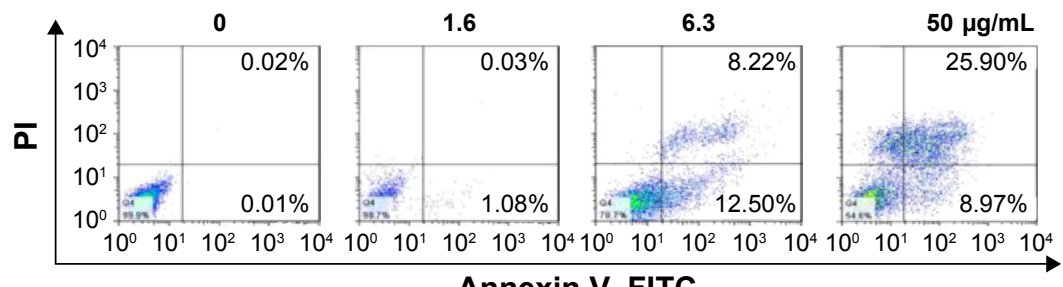

Annexin V-FITC

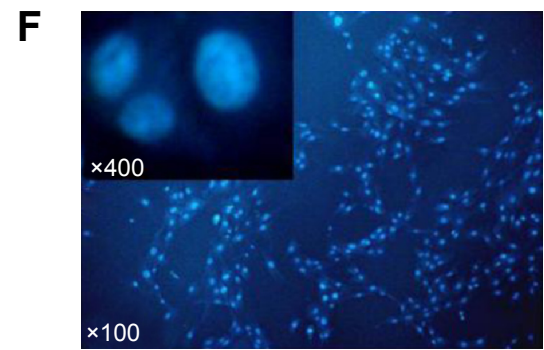

Control

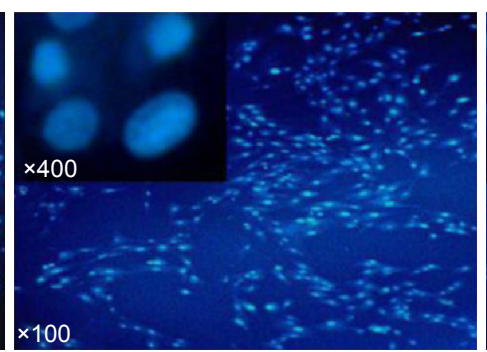

$\lg G$

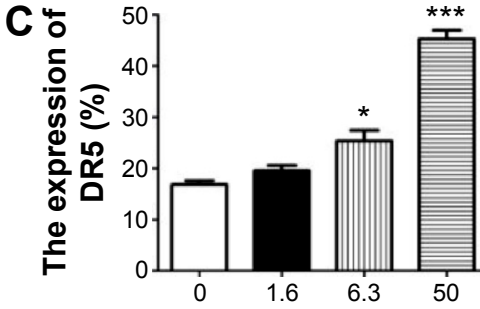

Concentration of anti-DR5 $\mathrm{mAb}(\mu \mathrm{g} / \mathrm{mL})$

E

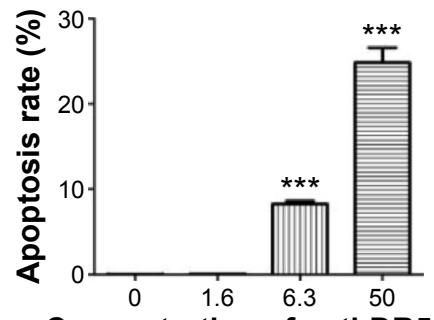

Concentration of anti-DR5 $\mathrm{mAb}(\mu \mathrm{g} / \mathrm{mL})$

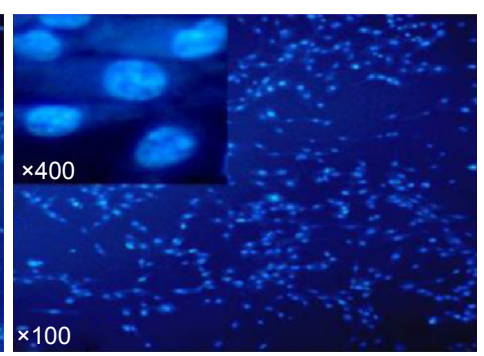

Anti-DR5 mAb

Figure 2 Anti-DR5 mAb induces fibroblast-like synovial cells (FLS) apoptosis.

Notes: All experiments were repeated three or more times. (A) The effect of anti-DR5 mAb (at I.6-50 $\mu \mathrm{g} / \mathrm{mL}$ ) on the proliferation of human FLS over 4, 12 , and 24 hours was detected by MTT analysis. Mouse IgG (at I.6-50 $\mu \mathrm{g} / \mathrm{mL}$ ) was applied to FLS for 24 hours as a control. (B and C) The expression of DR5 on FLS after treatment with 0, I.6, 6.3, and $50 \mu \mathrm{g} / \mathrm{mL}$ of anti-DR5 mAb for 24 hours was analyzed using flow cytometry. (D and E) Flow cytometric analysis of the mode of cell death of FLS treated with anti-DR5 mAb $(0,1.6,6.3$, and $50 \mu \mathrm{g} / \mathrm{mL}$ for 24 hours) after staining by annexin V-FITC/propidium iodide (PI). (F) FLS were treated with phosphate-buffered saline (PBS), mouse $\operatorname{lgG}(50 \mu \mathrm{g} / \mathrm{mL})$, or anti-DR5 mAb $(50 \mu \mathrm{g} / \mathrm{mL})$ for 24 hours, and then stained with Hoechst 33342 . Compared with the PBS group, the cell morphology of the anti-DR5 $\mathrm{mAb}$ group became round and the nucleus condensed, with significant nuclear fragmentation. These results show that the mode of cell death mediated by anti-DR5 mAb was mainly apoptosis. $* P<0.05 ; * * P<0.001 ; * * * P<0.000$ I.

Abbreviations: DR5, PI, death receptor 5; mAb, monoclonal antibody; h, hours.

the PBS group with increasing concentrations of anti-DR5 mAb. Compared with the PBS group, the level of TNF- $\alpha$ was decreased by $53.3 \%$ and $64.3 \%$ at anti-DR5 mAb concentrations of 6.3 and $50 \mu \mathrm{g} / \mathrm{mL}(P<0.05, P<0.01)$, respectively, and the level of IFN- $\gamma$ was decreased by $39.8 \%$ and $56.1 \%$ $(P<0.01, P<0.01)$, respectively (Figure 4A).

We also discovered that the expressions of TNF- $\alpha$ and IFN- $\gamma$ mRNA by FLS differed in the respective groups. The mRNA expressions of TNF- $\alpha$ and IFN- $\gamma$ were lower in the anti-DR5 $\mathrm{mAb}$ group than in the PBS group (Figure 4B and C).

\section{Discussion}

Human synovial cells are divided into three types: A, B, and C. Type B cells are known as FLS, and they are an important component of synovial tissue, secreting a variety 


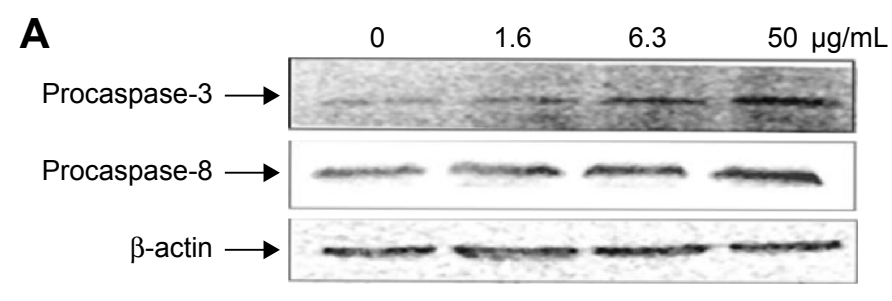

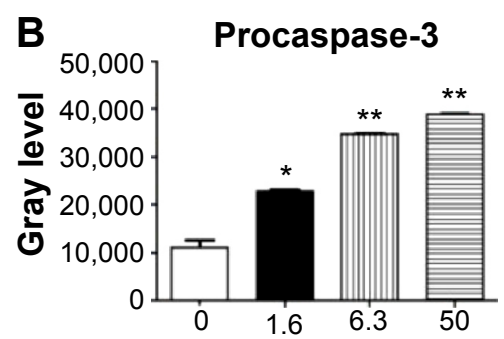

Concentration of anti-DR5 $\mathrm{mAb}(\mu \mathrm{g} / \mathrm{mL})$

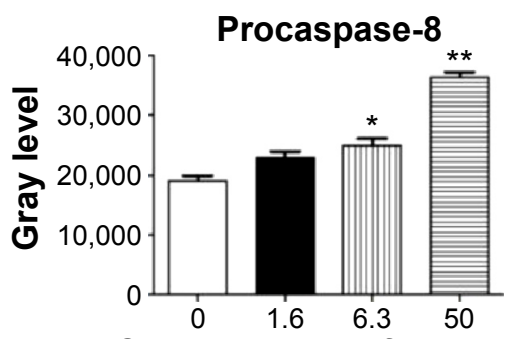

Concentration of anti-DR5 $\mathrm{mAb}(\mu \mathrm{g} / \mathrm{mL})$

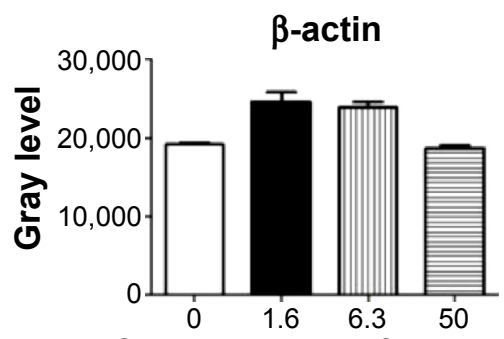

Concentration of anti-DR5 $\mathrm{mAb}(\mu \mathrm{g} / \mathrm{mL})$
C

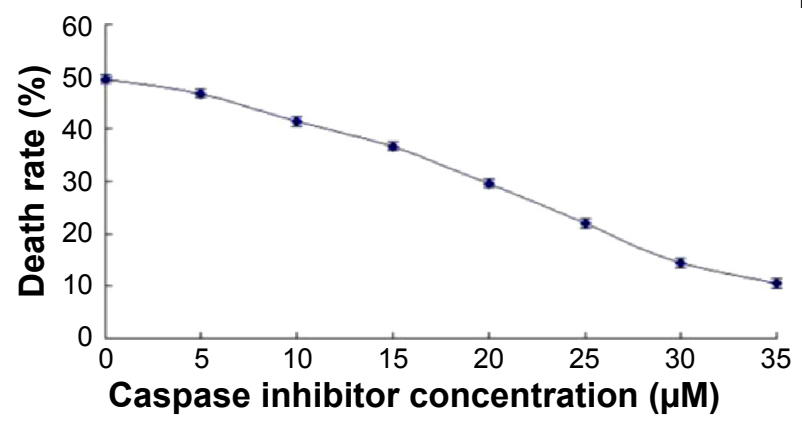

D Anti-DR5 mAb Caspase inhibitor Procaspase-9 $\longrightarrow$ Active caspase-9 $\longrightarrow$

Procaspase-3 $\longrightarrow$

Active caspase-3 $\longrightarrow$

$\beta$-actin $\longrightarrow$
Procaspase-9

E

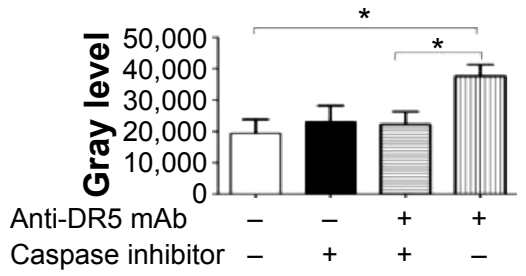

Procaspase-3

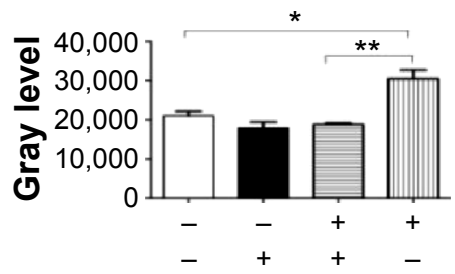

\section{Active caspase-9}

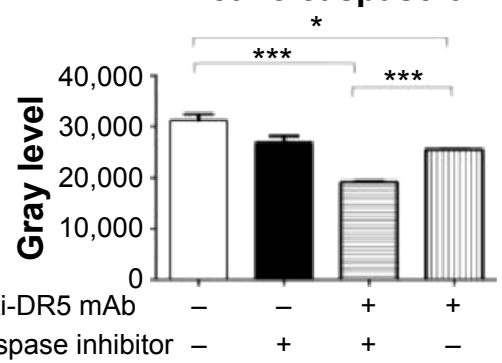

Active caspase-3

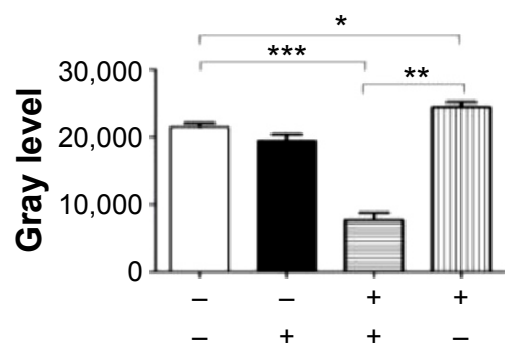

$\beta$-actin

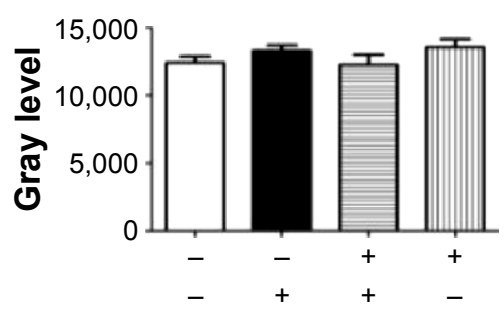

Figure 3 Mechanisms of anti-DR5 mAb induction of apoptosis in human fibroblast-like synovial cells (FLS).

Notes: (A) Human FLS were treated with $0,1.6,6.3$, and $50 \mu \mathrm{g} / \mathrm{mL}$ anti-DR5 mAb for 24 hours. The expressions of procaspase-3 and $-8 \mathrm{mere}$ analyzed by Western blot. As the concentration of anti-DR5 mAb increased, the expressions of procaspase- 3 and -8 , which are involved in the apoptosis pathway, increased compared with the phosphatebuffered saline group. (B) Grayscale analysis of (A). (C) FLS treated with $50 \mu \mathrm{g} / \mathrm{mL}$ of anti-DR5 mAb were treated with various concentrations of caspase inhibitor from 5 to $35 \mu \mathrm{M}$ for 24 hours. The inhibitory effects of anti-DR5 mAb on FLS were found to be dose dependent. (D) Western blot analysis of the expressions of procaspase-9, active caspase-9, procaspase-3, and active caspase-3 by FLS treated with anti-DR5 mAb $(50 \mu \mathrm{g} / \mathrm{mL})$ or caspase inhibitor (35 $\mu$ M) for 24 hours. (E) Grayscale analysis of (D). $* P<0.05 ; * * P<0.001 ; * * * P<0.0001$.

Abbreviations: DR5, death receptor 5; mAb, monoclonal antibody. 
A

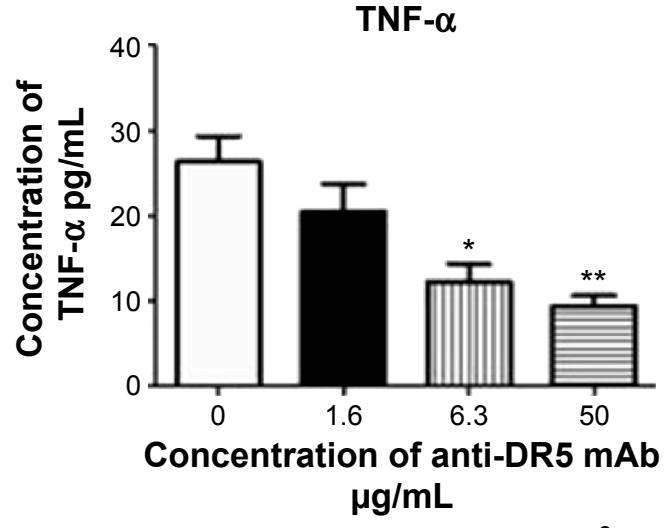

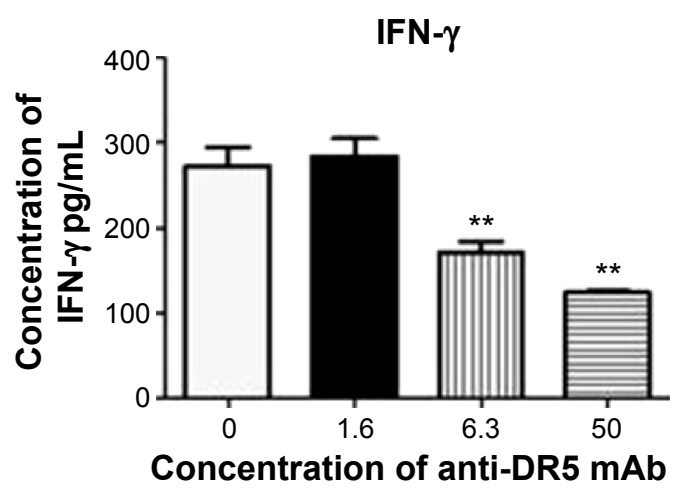

$\mu \mathrm{g} / \mathrm{mL}$

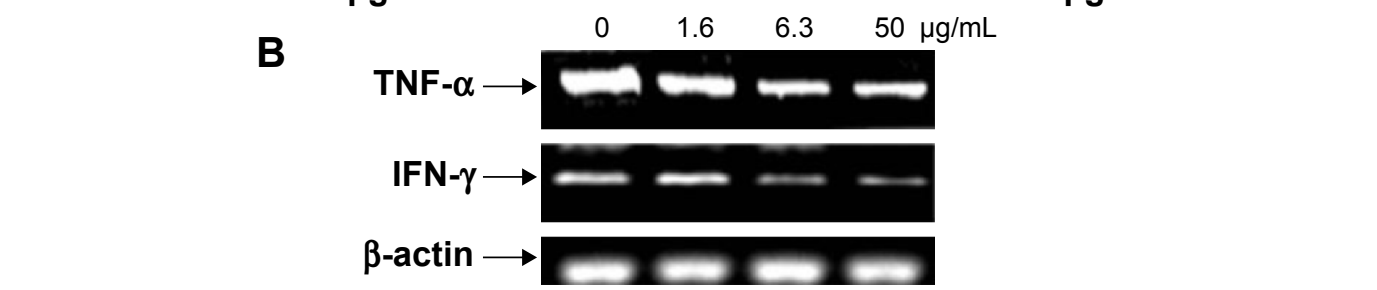

C

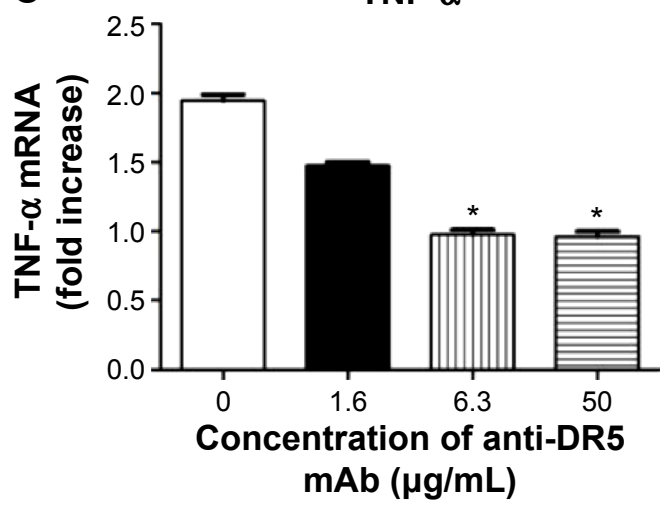

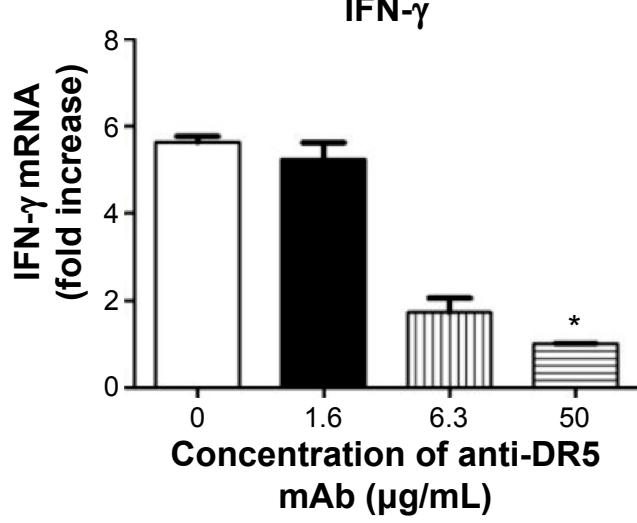

Figure 4 Anti-DR5 mAb decreases the expression of TNF- $\alpha$ and IFN- $\gamma$ by human fibroblast-like synovial cells (FLS).

Notes: Human FLS were treated with anti-DR5 mAb $(0,1.6,6.3$, and $50 \mu g / \mathrm{mL})$ for 24 hours. The cell culture supernatants were harvested and assessed for TNF- $\alpha$ and IFN- $\gamma$ by ELISA. The cells were collected for total RNA extraction with TRIzol, cDNA synthesis, and mRNA analysis by reverse transcription (RT) polymerase chain reaction (PCR). (A) The expressions of TNF- $\alpha$ and IFN- $\gamma$ in the supernatant were detected by ELISA. Compared with the phosphate-buffered saline (PBS) group (treated with $0 \mu \mathrm{g} / \mathrm{mL}$ anti-DR5 mAb), the secretion levels of TNF- $\alpha$ and IFN- $\gamma$ were decreased. (B and C) The expressions of TNF- $\alpha$ and IFN- $\gamma$ mRNA were detected by RT-PCR and quantitative PCR using $\beta$-actin as an internal standard. Compared with the PBS group, the expressions of TNF- $\alpha$ and IFN- $\gamma$ mRNA were decreased. $* P<0.05$ vs the PBS group; $* * P<0.001$ vs the PBS group.

Abbreviations: DR5, death receptor 5; mAb, monoclonal antibody; TNF- $\alpha$, tumor necrosis factor- $\alpha$; IFN- $\gamma$, interferon- $\gamma$.

of proteases, cytokines, and arachidonic acid metabolites that can damage the joint and accelerate the course of disease. ${ }^{11}$ Therefore, the isolation and identification of FLS forms an appropriate basis for the study of RA pathogenesis. In the present study, we used trypsin combined with type II collagenase to digest synovial joint tissue and obtain synovial cells, and then we isolated type B cells using differential adherence. Because type A cells do not have the ability to proliferate, they can be removed over multiple passages, leaving only the type B cells.

Prior studies have reported that, for both normal and chronic inflammation, synovial type A cells express a large number of white blood cell-, monocyte-, and macrophageassociated antigens, including CD45, CD13, CD14, CD16, CD31, CD32, CD33, CD37, CD39, CD54, CD64, CD68, CD71, and HLA-DR antigens, among others, ${ }^{9}$ but not vimentin. However, type B cells strongly express vimentin and do not express the white blood cell-, monocyte-, and macrophage-associated antigens listed above. Because the synovial cells we isolated here had a high expression of vimentin and did not express CD14 (Figure 1), we assumed that we had obtained type B cells, or FLS.

TRAIL plays an important role in RA. ${ }^{12}$ There are five different TRAIL receptors: TRAILR1 (DR4), TRAILR2 (DR5), 
TRAILR3 (DcR1), TRAILR4 (DcR2), and osteoprotegerin. ${ }^{13}$ TRAIL receptors are expressed in RA, and the expression of DR5 is increased in RA FLS. ${ }^{14}$ In a study using a mouse xenograft model of human RA, the anti-DR5 antibody significantly reduced the erosion of bone and cartilage damage. ${ }^{15}$ In another study, TRAIL adenovirus was transfected into the articular cartilage of a rabbit RA model, where it effectively reduced the symptoms of RA. ${ }^{16}$ In contrast, the symptoms of arthritis were aggravated in a collagen-induced arthritis model because TRAIL was immune-neutralized. ${ }^{16}$ In an earlier study, Li et al showed that anti-DR5 mAb can suppress the growth of FLS in a dose- and time-dependent manner after 12 hours. ${ }^{8}$ Miranda-Carús et al ${ }^{17}$ reported on a comparison of the clinical characteristics of three groups of RA patients: 1) no growth of synovial fluid fibroblasts; 2) growth of DR5+ synovial fluid fibroblasts; and 3) growth of DR5- synovial fluid fibroblasts. The synovial tissues and primary synovial fibroblast-like cells isolated from patients with RA in this study selectively expressed DR5. Interestingly, the expression of DR5 on FLS membranes was increased as the concentration of anti-DR5 mAb increased. We do not have research results proving that DR5 mRNA levels increased in this study, but Chen et al reported in analogous results that DR5 was expressed on the surface of the tested cell lines which correlated with the cellular susceptibility to apoptosis induced by rhTRAIL and the anti-DR5 antibody. ${ }^{18}$ This may very well explain why FLS exposed to higher doses of anti-DR5 mAb were highly susceptible to anti-DR5 mAb-induced apoptosis.

While it has been reported that anti-DR $5 \mathrm{mAb}$ can induce FLS apoptosis, the pathways involved in this effect remain unknown. DR5 combines with FADD to form a deathinducing signal complex. The hydrolysis of caspase- 8 initiates the two-cell apoptotic pathway and ultimately induces apoptosis by activating caspase- 3 and -7 , among others. ${ }^{19}$ In the present study, as the concentration of anti-DR $5 \mathrm{mAb}$ was increased, the expression of procaspase- 3 and procaspase- 8 also increased (Figure 3A). These results suggest that the caspase pathway may be involved in the apoptotic effect. Therefore, we used a caspase inhibitor, Z-VAD-FMK, after treating FLS with anti-DR5 mAb. The results showed that Z-VAD-FMK inhibited the apoptosis induced by antiDR5 mAb (Figure 3C). Compared with the anti-DR5 mAb group, the expressions of procaspase-9, procaspase-3, active caspase-3, and active caspase- 9 by FLS in the anti-DR $5 \mathrm{mAb}$ with caspase inhibitor group were significantly decreased. These findings indicate that anti-DR5 mAb induces FLS apoptosis through the caspase pathway.
Recently, Racke et $\mathrm{al}^{20}$ investigated whether assistant T-cells (Th1/Th2) play an important role in the pathogenesis of RA. Li et al reported that anti-DR5 TRA-8 can deplete IL-23-producing macrophages Th17 and Th1/17 and is also efficacious in reducing the severity of arthritis via a targeted depletion of macrophages and immunomodulation. ${ }^{21,22}$ In healthy people, Th1/Th2-type cytokines are in a state of balance, while the cytokine expression in RA patients is imbalanced. This imbalance in IFN- $\gamma$-secreting Th1 cells and IL-4-secreting Th2 cells may play a vital role in the pathogenesis of RA. ${ }^{23}$ Analysis of the cytokine mRNA and protein in RA tissues has revealed that many proinflammatory cytokines, such as TNF- $\alpha$, IL-1, IL-6, and GM-CSF, and chemokines such as IL-8, are abundant in all RA patients, regardless of treatment. ${ }^{14}$ TNF- $\alpha$ regulates cell survival, death, and proliferation. ${ }^{24}$ TNF- $\alpha$ binds and signals through tumor necrosis factor receptor I (TNFRI) and II (TNFRII), which are expressed at higher levels in RA FLS as compared with FLS from healthy or osteoarthritic patients. ${ }^{25}$ Therefore, we studied the effects of anti-DR5 mAb on the levels of pro- and anti-inflammatory cytokines in the cell culture supernatant of RA FLS. As shown in Figure 4, the expressions of TNF- $\alpha$ and IFN- $\gamma$ are decreased as the concentration of anti-DR5 $\mathrm{mAb}$ is increased. However, which pathways are activated by anti-DR $5 \mathrm{mAb}$, or how anti-DR $5 \mathrm{mAb}$ causes this effect, has not been reported. A previous experiment has shown that $\mathrm{NF}-\kappa \mathrm{B}$ stimulates the expression of various proinflammatory and immunomodulatory genes such as c-myc and TNF- $\alpha .{ }^{26}$ TNFRI and TNF- $\alpha$ knockout mice demonstrate mitigated apoptosis in large quantities of hepatoma cells due to a lack of RelA (p65). RelA-/- fibroblasts are more sensitive than wild-type $(\mathrm{RelA}+/+)$ fibroblasts to $\mathrm{TNF}-\alpha$-induced apoptosis. ${ }^{27}$ These studies confirm that NF- $\kappa \mathrm{B}$ protects cells from death receptor-mediated apoptosis. Because NF- $\kappa \mathrm{B}$ enters the nucleus, binding to target genes, and promoting the transcription of various cytokines, we think that NF- $\kappa B$ may be relevant to the process and deserves further study.

Further, it is reported that NF- $\kappa \mathrm{B}$ and Akt regulated TNF- $\alpha$-mediated apoptosis of RA synovial fibroblasts. ${ }^{28,29}$ There are reports suggesting that the TNF- $\alpha$-induced overexpression of SIRT1 in RA synovial cells contributes to chronic inflammation by promoting proinflammatory cytokine production and inhibiting apoptosis. ${ }^{30} \mathrm{Cytokines}$ are pleiotropic. TNF- $\alpha$ is a key component of RA pathogenesis, and blocking this cytokine is the most common strategy used to treat this disease. ${ }^{31}$ In the body, there are many regulatory mechanisms functioning at the same time to suppress the apoptosis induced by TNF- $\alpha$, which can explain very 
well how TNF- $\alpha$ levels decrease as apoptosis increases, as observed in this study.

\section{Conclusion}

Our findings demonstrate one of the molecular mechanisms behind the apoptosis induced by anti-DR5 $\mathrm{mAb}$ in human FLS, through the caspase pathway, and decreased secretions of TNF- $\alpha$ and IFN- $\gamma$. This study provides deeper insight into the potential development of anti-DR5 mAb as a treatment for RA.

\section{Acknowledgments}

This work was supported by the National Natural Science Foundation of China (grant number 81072472) and the Natural Science Foundation of Fujian Province, China (grant number 2012J01416).

\section{Disclosure}

The authors report no conflicts of interest in this work.

\section{References}

1. Panavi GS, Corrigall VM. Bip, an anti-inflammatory ER protein, is a potential new therapy for the treatment of rheumatoid arthritis. Novartis Found Symp. 2008;291:212-216.

2. Nakajima T, Aono H, Hasunuma T, et al. Apoptosis and functional Fas antigen in rheumatoid arthritis synoviocytes. Arthritis Rheum. 1995;38: 485-491.

3. Arend WP, Dayer JM. Inhibition of the production and effects of interleukin-1 and tumor necrosis factor alpha in rheumatoid arthritis. Arthritis Rheum. 1995;38:151-160.

4. Hessian PA, Highton J, Kean A, Sun CK, Chin M. Cytokine profile of the rheumatoid nodule suggests that it is a Th1 granuloma. Arthritis Rheum. 2003;48:334-338.

5. Londoño-Joshi AI, Oliver PG, Li Y, et al. Basal-like breast cancer stem cells are sensitive to anti-DR5 mediated cytotoxicity. Breast Cancer Res Treat. 2012;133(2):437-445.

6. Bevis KS, McNally LR, Sellers JC, et al. Anti-tumor activity of an antiDR5 monoclonal antibody, TRA-8, in combination with taxane/platinumbased chemotherapy in an ovarian cancer model. Gynecol Oncol. 2011;121(1):193-199.

7. Wang YG, Zhao KP, Chen JG, et al. The characteristic of an anti-human DR5 antibody A6. Cell Mol Immunol. 2008;5(3):183-188.

8. Li W, Liu Z, Zhuang G, et al. Anti-DR5 mAb ameliorate adjuvant arthritis rats through inducing synovial cells apoptosis. Exp Biol Med (Maywood). 2009;234(12):1468-1476.

9. Ando A, Hagiwara Y, Onoda Y, et al. Distribution of type A and B synoviocytes in the adhesive and shortened synovial membrane during immobilization of the knee joint in rats. Tohoku J Exp Med. 2010;221(2): 161-168.

10. Athanasou NA, Quinn J. Immunocytochemical analysis of human synovial lining cells: phenotypic relation to other marrow derived cells. Ann Rheum Dis. 1991;50(5):311-315.

11. Chabaud M, Lubberts E, Joosten L, van den Berg W, Miossec P. IL-17 derived from juxta-articular bone and synovium contributes to joint degradation in rheumatoid arthritis. Arthritis Res. 2001;3(3):168-177.

12. Bernardo AR, Cosgaya JM, Aranda A, Jiménez-Lara A. Synergy between RA and TLR3 promotes type I IFN-dependent apoptosis through upregulation of TRAIL pathway in breast cancer cells. Cell Death Dis. 2013;4:e479.
13. Simonet WS, Lacey DL, Dunstan CR, et al. Osteoprotegerin: a novel secreted protein involved in the regulation of bone density. Cell. 1997;89(2): 309-319.

14. Ichikawa K, Liu W, Fleck M, et al. TRAIL-R2 (DR5) mediates apoptosis of synovial fibroblasts in rheumatoid arthritis. J Immunol. 2003;171(2): 1061-1069.

15. Pan G, O'Rourke K, Chinnaiyan AM, et al. The receptor for the cytotoxic ligand TRAIL. Science. 1997;276(5309):111-113.

16. Taranto E, Leech M. Expression and function of cell cycle proteins in rheumatoid arthritis synovial tissue. Histol Histopathol. 2006;21(2): 205-211.

17. Miranda-Carús M, Balsa A, Benito-Miguel M, De Ayala C, Martín-Mola E. Rheumatoid arthritis synovial fluid fibroblasts express TRAIL-R2 (DR5) that is functionally active. Arthritis Rheum. 2004;50(9): 2786-2793.

18. Chen JJ, Mikelis CM, Zhang Y, Gutkind JS, Zhang B. TRAIL induces apoptosis in oral squamous carcinoma cells - a crosstalk with oncogenic Ras regulated cell surface expression of death receptor 5. Oncotarget. 2013;4(2):206-217.

19. Barczyk K, Kreuter M, Pryjma J, et al. Serum cytochrome c indicates in vivo apoptosis and can serve as a prognostic marker during cancer therapy. Int J Cancer. 2005;116(2):167-173.

20. Racke MK, Bonomo A, Scott DE, et al. Cytokine-induced immune deviation as a therapy for inflammatory autoimmune disease. J Exp Med. 1994;180:1961-1966.

21. Li J, Yang P, Wu Q, et al. Death receptor 5-targeted depletion of interleukin-23-producing macrophages, Th17, and Th1/17 associated with defective tyrosine phosphatase in mice and patients with rheumatoid arthritis. Arthritis Rheum. 2013;65(10):2594-2605.

22. Li J, Hsu HC, Yang P, et al. Treatment of arthritis by macrophage depletion and immunomodulation: testing an apoptosis-mediated therapy in a humanized death receptor mouse model. Arthritis Rheum. 2012;64(4):1098-1109.

23. Matyniak JE, Reiner SL. T helper phenotype and genetic susceptibility in experimental Lyme disease. J Exp Med. 1995;181:1251-1254.

24. Ware CF. Network communications: lymphotoxins, LIGHT, and TNF. Annu Rev Immunol. 2005;23:787-819.

25. Deleuran BW, Chu CQ, Field M, et al. Localization of tumor necrosis factor receptors in the synovial tissue and cartilage-pannus junction in patients with rheumatoid arthritis. Implications for local actions of tumor necrosis factor alpha. Arthritis Rheum. 1992;35(10):1170-1178.

26. Rudolph D, Yeh WC, Wakeham A, et al. Severe liver degeneration and lack of NF-kappaB activation in NEMO/IKKgamma-deficient mice. Genes Dev. 2000;14(7):854-862.

27. Beg AA, Baltimore D. An essential role for NF-kappaB in preventing TNF-alpha-induced cell death. Science. 1996;274(5288):782-784.

28. Xu H, He Y, Yang X, et al. Anti-malarial agent artesunate inhibits TNFalpha-induced production of proinflammatory cytokines via inhibition of NF-kappaB and PI3 kinase/Akt signal pathway in human rheumatoid arthritis fibroblast-like synoviocytes. Rheumatology. 2007;46(6): 920-926.

29. Zhang HG, Wang Y, Xie JF, et al. Regulation of tumor necrosis factor alpha-mediated apoptosis of rheumatoid arthritis synovial fibroblasts by the protein kinase Akt. Arthritis Rheum. 2001;44(7): 1555-1567.

30. Niederer F, Ospelt C, Brentano F, et al. SIRT1 overexpression in the rheumatoid arthritis synovium contributes to proinflammatory cytokine production and apoptosis resistance. Ann Rheum Dis. 2011;70(10): 1866-1873.

31. Semerano L, Thiolat A, Minichiello E, Clavel G, Bessis N, Boissier MC. Targeting IL-6 for the treatment of rheumatoid arthritis: Phase II investigational drugs. Expert Opin Investig Drugs. 2014;23(7): 979-999. 


\section{Publish your work in this journal}

OncoTargets and Therapy is an international, peer-reviewed, open access journal focusing on the pathological basis of all cancers, potential targets for therapy and treatment protocols employed to improve the management of cancer patients. The journal also focuses on the impact of management programs and new therapeutic agents and protocols on
Dovepress

patient perspectives such as quality of life, adherence and satisfaction. The manuscript management system is completely online and includes a very quick and fair peer-review system, which is all easy to use. Visit http://www.dovepress.com/testimonials.php to read real quotes from published authors.

Submit your manuscript here: http://www.dovepress.com/oncotargets-and-therapy-journal 